\title{
Perceived Attributes of Innovation: Perceived Security as an Additional Attribute to Roger's Diffusion of Innovation Theory
}

\author{
Hannah Ayaba Tanye \\ Limkokwing University of Creative Technology, Malaysia \\ Email: Hannahtanye@upsa.edu.gh
}

http://dx.doi.org/10.18415/ijmmu.v3i6.57

\begin{abstract}
The study attempts to contribute to the recent call on security issues in eLearning. Security issues in eLearning have been advanced at organizational level. These concerns had not been put in the light of effects on the diffusion of eLearning practice. ELearning involves the use of the web, digital media to deliver knowledge and skills. There is lack of the perspective of security issues at the individual level as a facilitator to the diffusion of innovations. This study proposes perceived security and how it affects the diffusion of eLearning practices in HEI as an additional perceived eLearning (innovation) attribute. The study seeks to find out the extent to which perceived security affect eLearning diffusion in the Universities. The research adopts a quantitative approach by the use of surveys. A survey has the capability of getting a wider and global perspective. Thus, these generalized views facilitate inform decision making in Universities' eLearning practice. The dependent variable for the quantitative approach is the diffusion of eLearning practice in the Universities. The independent variables are the perceived characteristics of eLearning system by students and the factors that characterize students' adoption of eLearning systems in Universities. The study found out that perceived security had the highest effect on eLearning diffusion among the students in the three Universities.
\end{abstract}

Keywords: Perceived attributes; eLearning; diffusion; perceived security

\section{Introduction}

Security concerns on the success and quality of eLearning is also a major concern to practitioners. There has been research on eLearning security measures. In Liu, Huang and Lin (2012) study they found that information security affects the system quality. They provided a top-down view of eLearning success for managers. Salisbury, W. D., Pearson, Pearson, \& Miller (2001) in their research found that perceived security had a greater impact on intention to buy than the ease and utility of the product. They stated that security issues have the potential to limit web-base customer activities. Flavián and Guinalíu (2006) in their study found that customer trust, perceived security, and privacy policy affects loyalty to a website. Research has shown that students are very concern of the safety of their data on learning systems. Shonola and Joy (2014) in their survey titled "Learners' Perception on Security Issues in M-learning" found that 
almost all students are very concern about the security of their data and only $3.33 \%$ of students indicated that security issues are neither important nor unimportant. Therefore it has been well established in literature that students are very concern about how safe the environment of their learning is.

These concerns had not been put in the light of effects on the diffusion of eLearning practice. ELearning involves the use of the web, all forms of digital media to deliver knowledge and skills. This study proposes perceived security and how it affects the diffusion of eLearning practices in HEI as an additional perceived eLearning (innovation) attribute.

\section{Innovations Diffusion}

There are different theories that try to explain the process of Diffusion. The two-step hypothesis which was first initiated by Lazarsfeld, Berelson and Gaudet (The Two step Flow Theory University of Twente, 2010). In this theory they stated that information from the media moves in two distinct stages." Another theory of Diffusion is the trickledown effect (Pettinger 2014), the Crossing of a Chasm by Geoffrey Moore, and the Technology Driven Models. The most widely accepted diffusion theory is the Diffusion of Innovations theory by Rogers.

Diffusion from dictionary definition is the "Spreading of Something Widely" or "the transmission of something widely". Diffusion is defined by Wikipedia as "the process by which a new idea or a new product is accepted by the market". Wikipedia further defined the Rate of Diffusion as "the speed that the new idea spreads from one consumer to the next".

"Diffusion of Innovations", was first published (first edition) in 1962, second edition in 1971, third edition in 1983, fourth edition in 1995, and the fifth edition in 2003. According to Rogers, the rate of adoption (ROA) is the speed at which society adopts an innovation. He defined diffusion as "the process in which an innovation is communicated through certain channels overtime among the members of a social system". He further stated that the communication in the message is concerned with new ideas (Rogers, 2003). The four main elements in Rogers Diffusion of Innovations are the perceived attributes of innovation, communication channels, time, and social system.

\section{The Key Element of Rogers Diffusion of Innovation}

The theory has four main elements namely: the perceived attributes of the innovation, communication channel, time, and the social system. 


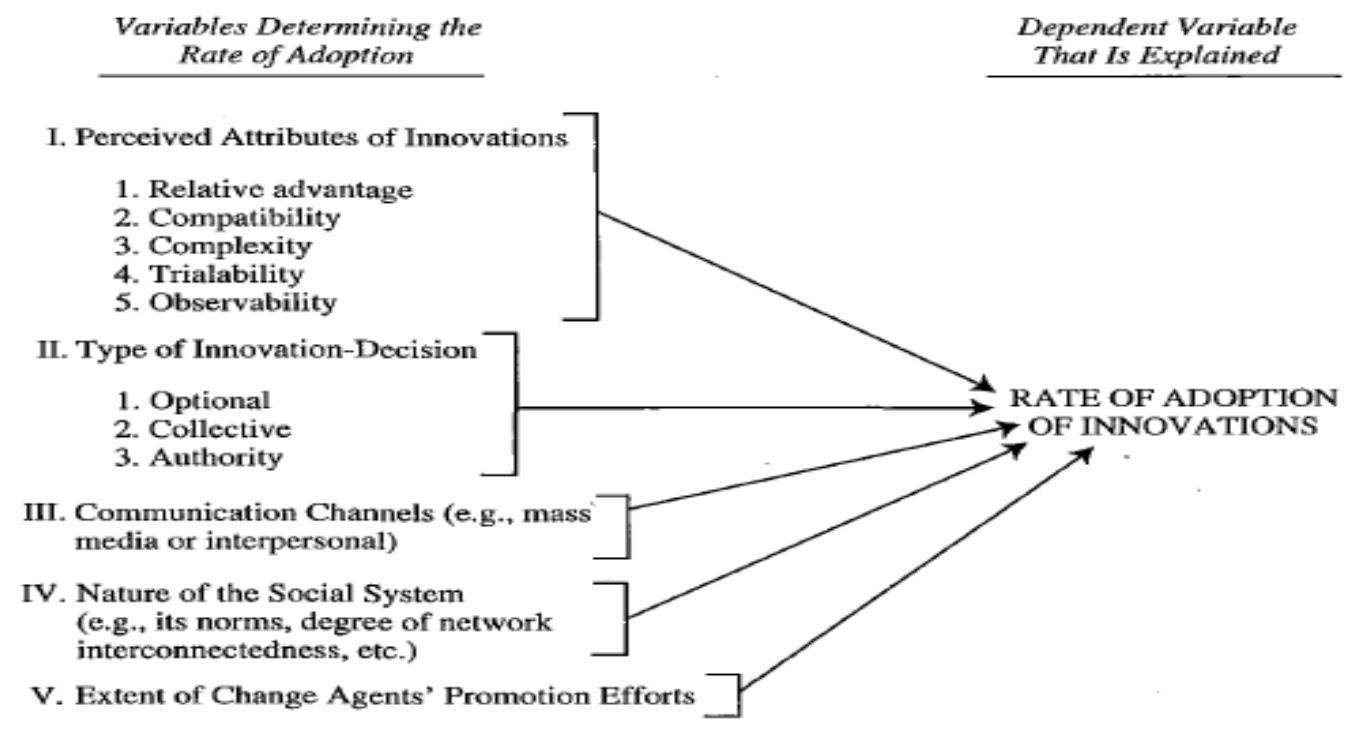

Fig. 1 Diffusion of Innovations- Fifth Edition (Rogers, 2003)

\section{The Perceived Attributes of the Innovation}

The perceived attributes of the innovation can determine the rate at which an innovation would diffuse. The innovation should be perceived to have the characteristics of relative advantage, compatibility, complexity, trialability, and observabilty. Thus a good innovation with good characteristics should be available, reliable, good response time, perceived to be easy to use, and adaptable (Delone \& McLean, 2003).

\section{Relative Advantage}

Rogers (2003) stated that "relative advantage is the degree to which an innovation is perceived as better than the idea it supersedes". The relative advantage can be measured in terms of convenience, economic terms and social prestige. According to Rogers the sub-dimensions of relative advantage are: economic profitability, low initial cost, a decrease in discomfort, social prestige, a saving of time and effort, and immediacy of results. A situation of over adoption of an innovation may occur due to lack of knowledge.

The perceived relative advantage depends on the nature of the innovation and the characteristics of the potential adopter as well. In regard to eLearning the relative advantage stem from cost, time, effort, comfort, and profitability. Ruiz, Mintzer, and Leipzig (2006) in their study found out that: "eLearning can result in significant cost savings up to $50 \%$ in the form of reduce instructor time, labour cost, and travelling cost, and reduce institutional infrastructure." In literature many argue that if lecturers are given incentives there is a higher likelihood for them to dedicate time to instructional design. This may be true but not entirely. Thus the factor of time and incentive must be improved together if better results are expected (Ruiz, Mintzer, \& Leipzig, 2006). As regard to over adoption in the case of eLearning, most institutions have adopted eLearning on inadequate knowledge (Rust \& Kim, 2012, Aggarwal \& Makkonen, 2009). 
Relative advantage according to Rogers is one of the strongest predictors of an innovation rate of adoption and mathematically it's calculated as the ratio of its benefits and the cost of adopting the innovation. The theory further suggested that adopter incentives can be used to increase relative advantage of an innovation and this can be initiated by higher level of social organization or community such as the government as a means of exerting influence on potential adopters' behaviour towards an innovation.

\section{Compatibility}

The innovation must also be compatible and Rogers defines compatibility as "the degree to which an innovation is perceived as being consistent with the existing values, past experience, and needs of potential adopters". Thus the innovation must be compatible with the users' needs. According to Rogers an innovation can be incompatible with one socio-cultural values and beliefs, previously introduced idea and client need for the innovation. The perceived compatibility of an innovation with a previous idea can influence adopters to misuse the innovation which can lead to over adoption or misadoption.

In relation to eLearning, HEI (higher educational institutions) belief in impacting knowledge and skills as well as meeting the needs of lecturers and students to ensure that the core business of the institutions are met. The basic aim of institutions has not changed with the adoption of eLearning but the "hows" the teaching and learning is done to achieve that aim have changed due to the advent of the internet and technology advancement (Martin, Diaz, Sancristobal, Gil, Castro \& Peire, 2011). In the case of eLearning over adoption or misadoption may occur if the previous ways of teaching leads to wrong application of eLearning to facilitate teaching. In the case of Distance learning, face to face pedagogy directly being applied to students may also be another case of over adoption and misadoption.

Thus there has been argument in literature for faculty to change their pedagogy to make eLearning effective in achieving the aim of imparting knowledge and skills effectively (Hardt \& Misite, 2008). The Adoption of eLearning as a delivery approach would only be effective if pedagogy involves a great deal of interactivity. Lecturers would have to give and encourage feedback to their students in a timely manner if interactivity and active participation are to be ensured (Brownell \& Tanner, 2012, Trukhacheva \& Krjaklina, 2011). Therefore the innovation must meet the needs of the client to ensure a high rate of innovation adoption.

\section{Complexity}

Complexity according to the Diffusion theory is "the degree to which the innovation is perceived as difficult to understand and use" and if there is the perception of relative difficulty (complexity) in its use potential adopters would resist.

The complexity of an innovation can very much depend on the characteristics of the adopter. eTeaching and eLearning is not for everyone (Aggarwal \& Makkonen, 2009). For instance students enrolled in eLearning programme or a distance learning student must have the discipline to learn with little to no supervision. Students who need lecturers to remind them constantly to submit assignments cannot be good distance learning students. Therefore would perceive it as complex and difficult to cope and dropout. 


\section{Trialability}

Like the saying goes, "practice makes perfect". The innovation diffusion also very much depends on how often it is used. Trialability is defined as "the degree to which an innovation may be experimented with on a limited basis. Trialability of any innovation is very important to dispel uncertainty. Innovations are readily accepted if it is tried and customized to suit adopters need.

In regard to eLearning, due to the expensive nature of building Learning Management Systems (LMS) from scratch, most institutions especially in third world countries buy off-the-shelf software. Some institutions limit trialability to IT experts and deploy it to the University community due to cost implications.

\section{Observability}

Lastly, there should be observability, which Rogers described as "the degree to which the results of the new innovation are visible to others." The benefits of the innovation being obvious to others would also ensure diffusion. The observability of an innovation can be facilitated by instituting incentive for diffusers. According to Rogers a diffuser is "someone who recruits an adopter of innovation".

The rewards of adopting eLearning are not immediate which makes observability of the innovation difficult. Collaboration and communications of various institutions on the innovation use would foster observability. Institutions are able to share experiences and learn from other users what they have been able to overcome in the implementation of eLearning. According to Elameer and Idrus (2011) collaboration should be initiated at the national level to ensure that valued resources are not drained (Durah, Alraddadi, Alzubi, \& Alzubi, 2011).

\section{Communication Channels}

The rate of adoption of innovation is also dependent on the communication channels. In Rogers' fifth edition communication is defined as "information exchange through which one individual communicates a new idea to one or several others. Communication can be channelled by mass media which are designed to reach a large number of potential adopters or interpersonal. Mass media is strictly cosmopolite and interpersonal can either be localite or cosmopolite. Rogers stated that: "interpersonal networks often allow them to overcome the social-psychological barriers of selective exposure, selective perception, and selective retention".

The inter-personal communication has a higher effect on potential adopters to adopt an innovation. The theory further suggested that this form of communication is very effective when the persons involved are of the same socioeconomic status, and same education. The type of communication channel at the stages of the decision making process is very important. For instance, at the knowledge level mass media is an effective channel to use and at the persuasion stage interpersonal communication is more effective and that in rare cases mass media can be used in the persuasion stage (Rogers, 2003). The cosmopolite and the localite channels are used in the knowledge stage and the persuasion stage respectively. 


\section{Time}

The time element of the rate of innovation adoption can be defined as stated by Rogers in terms of "the decision process", "innovativeness", and "rate of adoption". The decision process involves five stages namely: knowledge, persuasion, decision, implementation and confirmation. The innovativeness is how the adopter perceived the newness of the innovation. The rate of adoption is the "the number of members in the system who adopt the innovation in a given time period." Mostly the time element in behavioural science research is simply ignored. This is not so with Diffusion of Innovation. Time is one key factor in the diffusion process. Time dimension is also an important factor in the Innovativeness of adopter categories. Rogers defined innovativeness as "the degree to which an individual or other unit of adoption is relatively earlier in adopting new ideas than the other members of a system".

\section{Social System}

The social system element of rate of innovation adoption is defined by Rogers as "a set of interrelated Units that are engaged in a joint problem solving to accomplish a common goal." In any social system there are opinion leaders, change agents and aides. There can be three different types of innovation decision in a society. These are optional, collective, authority decisions process. Roger mentioned the strategy of injecting the technology. Injection gives a notion of an outside force, which is certainly from an authority class of decision makers.

The three categories of decisions cannot be exclusive. One group certainly gives rise to other groups. For instance Roger further stated that for diffusion to occur in an organization collective innovation decision and authority is needed for organization-wide adoption. Thus since organizations are made up of individuals. It presupposes that a Top-Down decision has to be made. But since strictly TopDown cannot sustain the propagation of the innovation to span the spectrum of change, a mixer of a bottom-up would blend well and the organization would have the desired diffusion.

Roger in his work also brought to the fore how social norms and standards of acceptance can hinder the adoption of an innovation. Therefore in the diffusion of innovation, it cannot be expected that individuals in a system would individualistically culminate in creating diffusion. These individuals are in a system, a medium, etc. A force of injection has to be originated. He therefore added for innovation in organizations, collective or Authority decision processes are more appropriate. The study is of the view that the state should be that force of injection leading the way for a top-down, bottom-up and participatory approach for the eLearning practice to be diffuse in HEI (Higher Educational Institutions).

A social system is made up of individuals. These individuals do not adopt an innovation at the same time. Therefore these individuals are classified into adopter categories based on "when they first begin using a new idea" How earlier an individual adopts an innovation relative to other individuals in the social system is termed innovativeness (Rogers ,2003). 


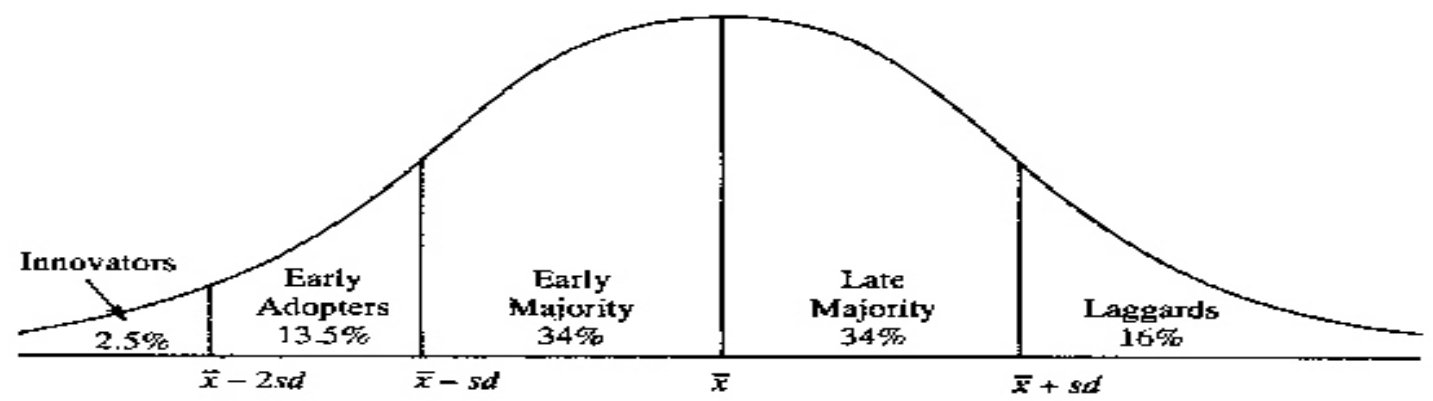

Fig. 2 Adopter Categories (Rogers, 2003)

\section{Methodology and Data Collection}

The research adopts a quantitative approach by the use of surveys. A survey has the capability of getting a wider and global perspective. Thus, these generalized views facilitate inform decision making in Universities' eLearning practice. The dependent variable for the quantitative approach is the diffusion of eLearning practice in the Universities. The independent variables are the perceived characteristics of eLearning system by students and the factors that characterize students' adoption of eLearning systems in Universities.

480 students responded to the questionnaire. The quantitative questionnaire is made up of three sections. The section one comprises of the background information. Section two comprises of the perceived innovation variables. Relative Advantage has nine data items, compatibility has four data items, complexity has eight data items, trialability has ten data items, observability has six data items, and security has six data items. Section three is adopter category with nine data items. Questions had four options to choose from on the Likert Scale. Strongly Agree, Agree, disagree, and strongly disagree.

\section{Analysis and Discussions}

The aim of the research was to determine the extent of the effect of perceived eLearning attributes by students on its diffusion. The effect of perceived security which is an introduced attribute to Roger's perceived attributes of innovation on eLearning diffusion.

The study aimed at answering the following questions and testing the following hypothesis:

RQ1: What is the extent that perceived attributes of eLearning system influence its diffusion?

RQ2: What extent does perceive security affect eLearning system diffusion?

RQ3: What extent does the adopter type affect eLearning System Diffusion 
Table 1 Descriptive Statistics

\begin{tabular}{|l|l|l|l|l|l|}
\hline Descriptive Statistics & N & Minimum & Maximum & Mean & $\begin{array}{l}\text { Std. } \\
\text { Deviation }\end{array}$ \\
\hline Sex & & & & & \\
\hline Age & 432 & 1 & 2 & 1.50 & .501 \\
\hline Level Of Study & 446 & 1.00 & 5.00 & 2.4376 & .77016 \\
\hline Course of Study & 465 & 1.00 & 4.00 & 1.8043 & .55163 \\
\hline Valid N (listwise) & 409 & & & & \\
\hline
\end{tabular}

In summary a total of four hundred and thirty-two students (432) indicated their sex. Four hundred and fifty-seven (457) indicated their age. Those who indicated their level of study were four hundred and forty six (446). And lastly four hundred and sixty-five (465) indicated their course of study. The mean and standard deviation for sex is 1.5 and 0.501 respectively. That for Age is 2.44 and 0.77 respectively. That of Level of study is 2.59 and 1.17 respectively. That for Course of study is 1.80 and 0.55 respectively. All values have been approximated to 2 decimal places.

\section{The Path Co-efficient}

The path co-efficient is a measure of correlation. In this analysis the emphasis is not on whether an independent variable has an additional effect on a dependent variable. The emphasis is on the whole model. Whether, to accept, modify, or reject the model. The direct effect of Adopter category on eLearning diffusion is 0.28 , that of compatibility is 0.099 , that of complexity is 0.07 , that of observability is 0.122 , that of relative advantage is 0.162 , that of security which is the highest is 0.424 and that of trialability is 0.135 . The direct effect of the variables in percentage is illustrated in the pie chart below. 
Table 2 Path Co-efficient

\begin{tabular}{|l|l|l|l|l|l|l|l|l|}
\hline & Adop. & Comp. & Compl & Obsv. & RelAd & Sec. & Tria & elDiff \\
\hline Adopter Category & & & & & & & & 0.398 \\
\hline Compatibility & & & & & & & & 0.076 \\
\hline Complexity & & & & & & & & 0.088 \\
\hline Observability & & & & & & & & 0.113 \\
\hline Relative Advantage & & & & & & & & 0.115 \\
\hline Security & & & & & & & & 0.442 \\
\hline Trialability & & & & & & & & 0.087 \\
\hline eLearning Diffusion & & & & & & & & \\
\hline
\end{tabular}

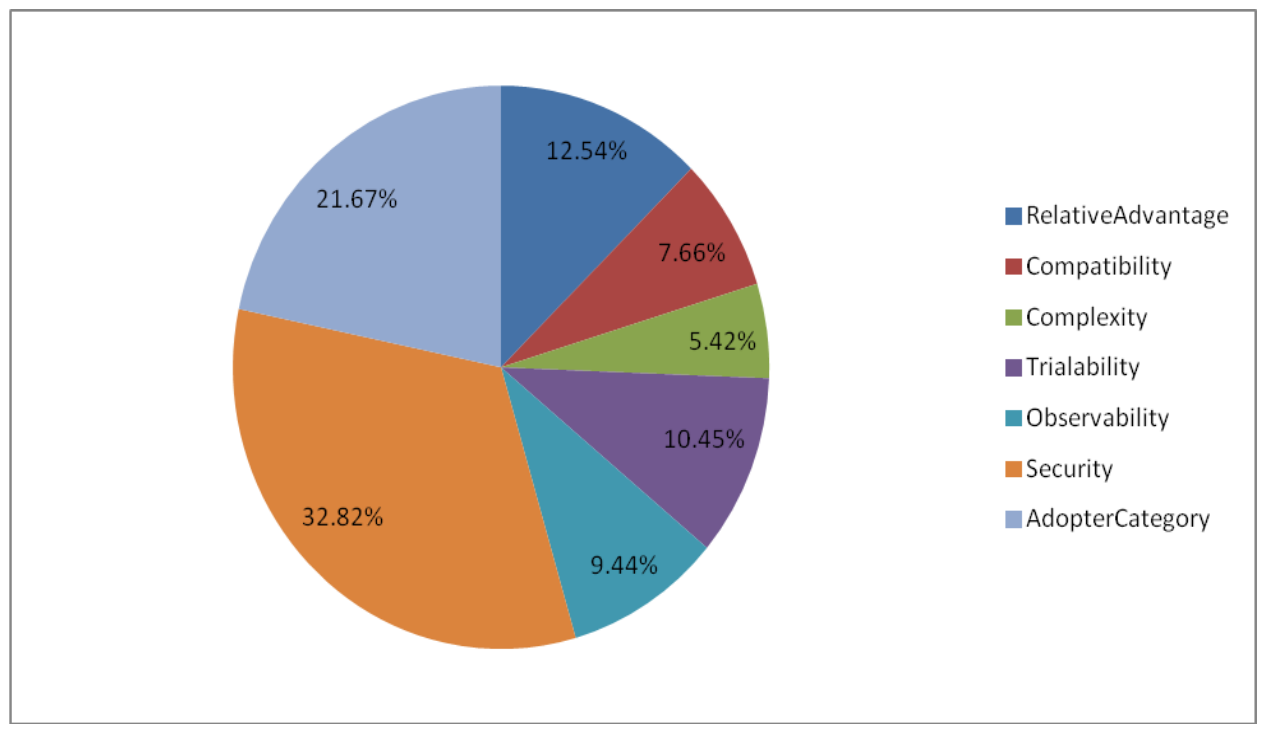

Fig. 3 Path Co-efficient Pie Chart

The extent of attributes effect on eLearning Diffusion in the Universities

The Perceived attributes of eLearning Diffusion 


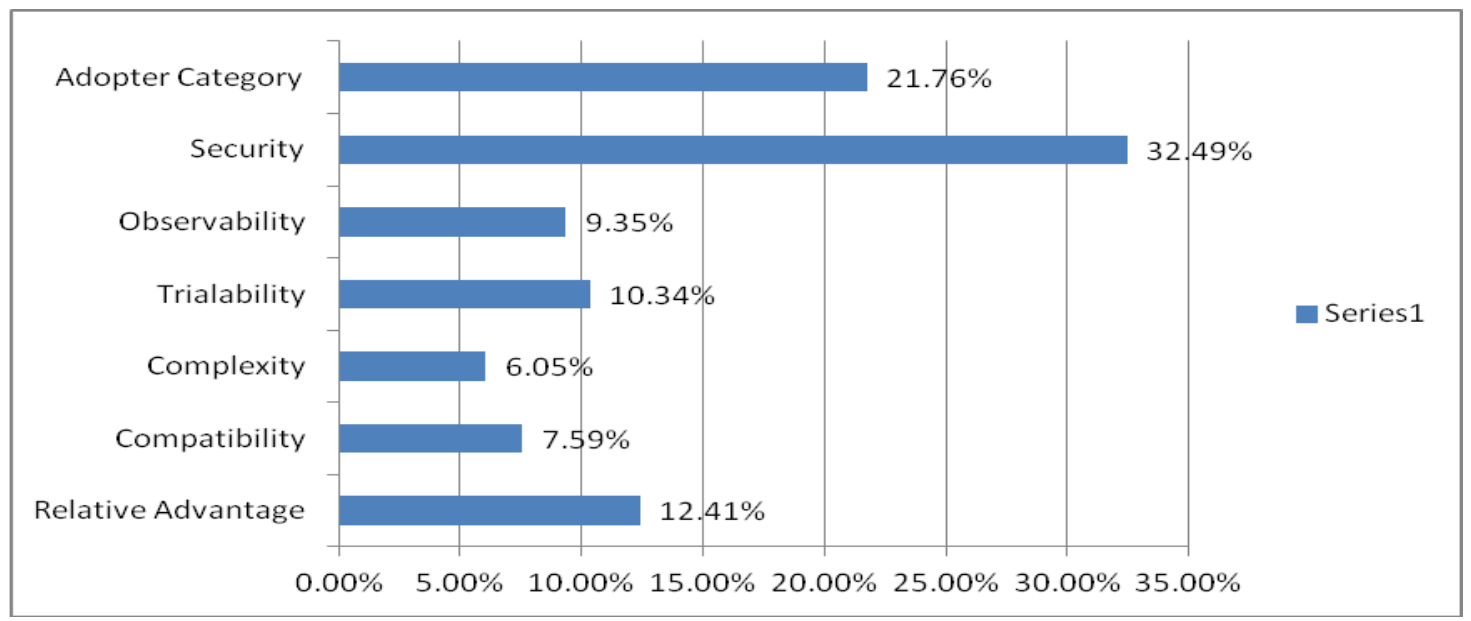

Fig. 4 Extent of effect of Independent variables

The percentage of perceived relative Advantage is $12.41 \%$, Compatibility is $7.59 \%$, complexity is $6.05 \%$, Trialability is $10.34 \%$ and Observability is $9.35 \%$. In all the total effect of the five traditional perceived attributes of eLearning diffusion is $45.75 \%$.

The implementation of eLearning for the University to benefit from all its good aspect, but at times this is not so. There can be negative occurrences where the innovation implementation cannot yield the effect that is desired. Roger calls this over adoption. According to Roger this can occur due to lack of knowledge in the application of the innovation. Literature has proved that many institutions adopt eLearning based on scanty knowledge thus the benefits sought is not being able to be realized (Rust \& Kim, 2012, Aggarwal \& Makkonen, 2009).

Though all attributes had a positive effect on eLearning diffusion, there is still room for more diffusion. The Diffusion of innovations suggested that adopter incentives can be used to increase relative advantage of an innovation and this can be initiated by higher level of social organization or community such as the government as a means of exerting influence on potential adopters' behaviour towards an innovation.

The theory further suggests that, the compatibility can sometimes lead to the misuse of the innovation which can lead to overadoption or misadoption. In the case of eLearning over adoption or misadoption may occur if the previous ways of teaching leads to wrong application of eLearning to facilitate teaching. In the case of Distance learning, face to face pedagogy directly being applied to students may also be another case of over adoption and misadoption. Ogunlela and Ogunleye (2015) stated "the QA mechanism being adopted for programmes in conventional higher institutions cannot be superimposed on those of ODL and dual mode institutions. The solution for this is to adopt a pedagody that is eLearning compatible and not superimpose face-face for eLearning. Furthermore, Lecturers would have to give and encourage feedback to their students in a timely manner if interactivity and active participation are to be ensured (Brownell \& Tanner, 2012, Trukhacheva \& Krjaklina, 2011).

The attribute complexity had the least influence on eLearning diffusion. At times the complexity of a system can be due to the kind of adopter also. For distance learning students, they are expected to do much on their own due to less contact hours with lecturers. To resolve this situation, students must be able to know their responsibilities and have the minimal requisite skills to search for databases online and be taught basic referencing to avoid plagiarism. Besides, student can be screened during admission or be involved in a pre-class to prepare them as distance learning students. Without pre- preparation, some of 
them are bound to dropout because the whole eLearning programme would seem complex. As Aggarwal and Makkonen, (2009) puts it eTeaching and eLearning is not for everyone

From the findings, Out of the 480 respondents, 440 answered the question "I was permitted to use eLearning on a trial basis long enough to see what it could do." $17.73 \%$ strongly agree, $32.27 \%$ agree, $39.09 \%$ disagree, and $10.91 \%$ strongly disagree. In general $50 \%$ of distance learning students do not try eLearning systems before they are launched. Universities have decried the cost for the trying of innovation by students before they are launched. Some institutions allow a few lecturers with IT staff to try and then the innovation is launched. On the contrary, the innovation would be used mostly by the students so therefore, institutions should try as much to allow some pretesting to further boost the diffusion process. From the regression analysis of the effect of attributes on each other, this can also be improved by increasing the innovation compatibility, reducing its complexity, and also increasing observability.

Out of 439 respondents to the question "eLearning tools and systems are not very visible in my Institution". 54\% generally agree whilst $46 \%$ generally disagree. Students are not permitted to use eLearning on a trial basis long enough to see what it could do. Out of the 439 respondents who answered the question "I have not seen many others using a eLearning in my Institution.", $13.67 \%$ strongly agree, $36.90 \%$ agree, $36.37 \%$ disagree, and $12.76 \%$ strongly disagree. In general, $50.57 \%$ have not seen many others using eLearning in their institution. From the findings, observability is woefully inadequate for the distance learning students. From the diffusion of innovations theory, the observability of an innovation can be facilitated by instituting incentive for diffusers. Collaboration and communications of various institutions on the innovation use would foster observability. According to Elameer and Idrus (2011) collaboration should be initiated at the national level to ensure that valued resources are not drained (Durah, Alraddadi, Alzubi, \& Alzubi, 2011).

\section{Introduction of a New Attribute- "Perceive security" to the eLearning Diffusion}

The findings of the study show that perceived security has the greatest impact of eLearning diffusion. Students are increasingly being concerned by their security in the adoption of innovations. A good information security ensures quality eLearning system (DeLone \& McLean, 2003).

In Liu, Huang and Lin (2012) study they found that information security affects the system quality. Salisbury, W. D., Pearson, Pearson, \& Miller (2001) in their research found that perceived security had a greater impact on intention to buy than the ease and utility of the product.

Therefore, the study suggests the addition of perceived security as an additional perceived attributes to Rogers theory of Diffusion of Innovations.

\section{Student Characteristics and eLearning System}

As the theory states, in a typical society there are ideally five types of adopter category: the innovators, early adopters, the early majority, late majority and the laggards. The study indicated that the student group were made up of all these five categories. The innovators and early adapters can serve as diffusers in any society. Diffusers can include opinion leaders. The influence of the opinion leaders help to create a critical mass to adopt the innovation. Adopters had to be encouraged in their knowledge, persuasion, decision, implementation and confirmation stages in the adoption of eLearning. The adopter categories are therefore cauterized by the degree of their innovativeness. 


\section{Conclusion}

Perceived security has the highest influence of the eLearning diffusion. This shows that students' are very concern about their data on eLearning systems. Security shows a $32.82 \%$ influence on eLearning diffusion.

The study shows that $17.83 \%$ disagree or strongly disagree that their institution maintains appropriate protection of information assets. Though $82.17 \%$ strongly agree or agree there is still room for the improvement of marinating the assets. $81 \%$ strongly agree and agree that their institution achieves security compliance with legislation or industry. $19 \%$ strongly disagree or disagree with the statement. Security issues look generally good but Universities can make improvement.

Aside Universities issues on security, the study recommend the addition of perceived security to the Rogers diffusion of innovation theory.

\section{References}

\section{Books}

Rogers, E. M. (1962). Diffusion of innovations. New York: Free Press.

Rogers, E. M. (1983). Diffusion of innovations. New York: Free Press.

Rogers, E. M. (1995). Diffusion of innovations. New York: Free Press.

Rogers, E. M. (2003). Diffusion of innovations. New York: Free Press.

\section{Articles}

Aggarwal AK \& Makkonen P ,2009, Critical success factors for globalised e-learning, International Journal of Innovation and Learning, Vol. 6, issue 1, DOI: 10.1504/IJIL.2009.021687.

Brownell, SE., \& Tanner, KD., 2012, 'Barriers to faculty pedagogical change: lack of training, time, incentives, and... tensions with professional identity?', CBE-Life Sciences Education, 11(4), 339-346.

Delone, W. H., \& McLean, E. R.201992, (2003). The DeLone and McLean model of information systems success: a ten-year update. Journal of management information systems, 19(4), 9-30.

Durah, K., Alraddadi, A., Alzubi, O., \& Alzubi, B. (2011). Strategic Elearning.Global Journal of Computer Science and Technology, 11(2).

Elameer, A. S., \& Idrus, R. M. (2011). National E-Learning Strategy to Enhance and Enrich the Iraqi Universities. Online Submission.

Flavián, C., \& Guinalíu, M. (2006). Consumer trust, perceived security and privacy policy: three basic elements of loyalty to a web site. Industrial Management \& Data Systems, 106(5), 601-620.

Liu, Y. C., Huang, Y. A., \& Lin, C. (2012). Organizational factors' effects on the success of e-learning systems and organizational benefits: An empirical study in Taiwan. The International Review of Research in Open and Distributed Learning, 13(4), 130-151. 
Martin S., Diaz G., Sancristobal E., Gil R., Castro M., \& Peirel J., (2011), New technology trends in education: Seven years of forecasts and convergence, Computers \& Education 57, 1893-1906.

Ogunlela, V. B., \& Ogunleye, B. O. (2015). Promoting Quality Assurance Practices for ODL Programmes in West African Higher Education Institutions: The Role of RETRIDAL. International Open and Distance Learning Journal, 1(1).

Ruiz, J. G., Mintzer, M. J., \& Leipzig, R. M. (2006). The impact of e-learning in medical education. Academic medicine, 81(3), 207-212.

Rust VD, Kim S., 2012, The Global Competition in Higher Education, World Studies in Education, 13(1), p 5-20.

Shonola A \& Joy M., (2014) Mobile Learning Security Concerns from University Students' Perspectives, DOI: 10.1109/IMCTL.2014.7011125 Conference: International Conference on Interactive Mobile Communication Technologies and Learning.

Trukhacheva N, Trukhacheva S \& Krjaklina T, (2011) "The Impact of E-Learning on Medical Education in Russia”.

W. D Salisbury, R A. Pearson, Pearson AW, Miller DW, (2001) "Perceived security and World Wide Web purchase intention", Industrial Management \& Data Systems,101(4), pp.165 - 177.

\section{Web Publication}

The Two step Flow Theory University of Twente 2010 Retrieved from https://www.utwente.nl/cw/theorieenoverzicht/Theory\%20Clusters/Mass\%20Media/Two_Step_Flow_T heory-1/, June 2015.

\section{Copyrights}

Copyright for this article is retained by the author(s), with first publication rights granted to the journal.

This is an open-access article distributed under the terms and conditions of the Creative Commons Attribution license (http://creativecommons.org/licenses/by/4.0/). 